\title{
An Early Feeding Practices Intervention for Obesity Prevention
}

Lynne Allison Daniels, PhD ${ }^{a, b, c}$, Kimberley Margaret Mallan, PhD ${ }^{a, b}$, Jan Maree Nicholson, PhD ${ }^{\text {,e }}$, Karen Thorpe, PhD ${ }^{a, f}$, Smita Nambiar, PhD ${ }^{\mathrm{a}, \mathrm{b}}$, Chelsea Emma Mauch, BSc(Hons) ${ }^{\mathrm{c}}$, Anthea Magarey, $\mathrm{PhD}^{\mathrm{b}, \mathrm{c}}$

OBJECTIVE: Report long-term outcomes of the NOURISH randomized controlled trial (RCT), which evaluated a universal intervention commencing in infancy to provide anticipatory guidance to first-time mothers on "protective" complementary feeding practices that were hypothesized to reduce childhood obesity risk.

METHODS: The NOURISH RCT enrolled 698 mothers (mean age 30.1 years, SD $=5.3$ ) with healthy term infants (51\% female). Mothers were randomly allocated to usual care or to attend two 6-session, 12-week group education modules. Outcomes were assessed 5 times: baseline (infants 4.3 months); 6 months after module 1 (infants 14 months); 6 months after module 2 (infants 2 years) and at 3.5 and 5 years of age. Maternal feeding practices were self-reported using validated questionnaires. BMI Z-score was calculated from measured child height and weight. Linear mixed models evaluated intervention (group) effect across time.

RESULTS: Retention at age 5 years was $61 \%$. Across ages 2 to 5 years, intervention mothers reported less frequent use of nonresponsive feeding practices on 6 of 9 scales. At 5 years, they also reported more appropriate responses to food refusal on 7 of 12 items ( $P s \leq .05)$. No statistically significant group effect was noted for anthropometric outcomes (BMI Z-score: $P=.06$ ) or the prevalence of overweight/obesity (control 13.3\% vs intervention $11.4 \%, P=.66$ ). conclusions: Anticipatory guidance on complementary feeding resulted in first-time mothers reporting increased use of protective feeding practices. These intervention effects were sustained up to 5 years of age and were paralleled by a nonsignificant trend for lower child BMI Z-scores at all postintervention assessment points.

WHAT'S KNOWN ON THIS SUBJECT: "Protective" complementary feeding practices that promote self-regulation of intake and development of healthy food preferences have been positively associated with healthy child eating patterns and growth. There are few high-quality trials evaluating feeding practice interventions; none has reported long-term outcomes.

WHAT THIS STUDY ADDS: This large randomized controlled trial demonstrates that anticipatory guidance on the "how" of complementary feeding resulted in more protective feeding practices. These intervention effects were sustained for 3 years and translated into commensurate trends in obesity risk.
${ }^{a}$ Institute of Health and Biomedical Innovation, ${ }^{b}$ School of Exercise and Nutrition Sciences, ${ }^{e}$ Centre for Learning Innovation, and ${ }^{f}$ School Psychology and Counselling, Queensland University of Technology, Brisbane, Australia; ${ }^{c}$ Department Nutrition and Dietetics, Flinders University, Adelaide, Australia; and ${ }^{d}$ La Trobe University, Melbourne, Australia

Dr Daniels conceived the study; led the design, successful funding applications, and overall implementation of the study; and wrote the first draft of the paper; Dr Mallan undertook the statistical analysis and drafted the Results and Methods sections; Dr Nicholson contributed to funding applications, intervention development, and design of outcome assessments; Dr Thorpe contributed to funding application and measure development; Dr Nambiar coordinated study implementation and contributed to data collection and entry; Ms Mauch contributed to the design and delivery of the intervention modules and data collection; Dr Magarey contributed to the design, funding applications, development of the intervention, and lead implementation the Adelaide site; all authors contributed to interpretation of results and preparation of the manuscript and approved the final manuscript as submitted.

This trial has been registered at http://www.anzctr.org.au (registry number 12608000056392).

www.pediatrics.org/cgi/doi/10.1542/peds.2014-4108

DOI: $10.1542 /$ peds.2014-4108

Accepted for publication Apr 3, 2015 
The early life environment has a profound life-course effect on social, cognitive, behavioral, and health outcomes, including obesity. ${ }^{1,2}$ In the fetal and early life periods, interactions between biology and environmental exposures produce epigenetic effects that influence the risk of childhood obesity. ${ }^{3,4}$ Hence, early life interventions, when both behavior and biology are "plastic," have potential both to ameliorate epigenetic effects and increase resilience to the behavioral and metabolic challenges posed by an obesogenic environment. ${ }^{1}$ Early feeding practices likely compound increased obesity risk conferred by genetic predisposition and prenatal factors such as excess gestational weight gain. ${ }^{4}$ The way that infants are fed ("feeding practices") programs taste preferences and appetite regulation and lays the foundation for lifelong eating patterns. ${ }^{5-7}$ The many protective effects of breastfeeding, including healthy growth patterns, are clear. ${ }^{8-10}$ The impact of the process of complementary feeding that enables transition from milk feeding to adult eating patterns has received less attention. "Protective" complementary feeding practices that promote selfregulation of intake and development of healthy food preferences have been positively associated with healthy child eating patterns and growth. ${ }^{11-15}$ Selfregulation of intake is supported by responsive feeding that recognizes and responds appropriately to infant cues of hunger and satiety, trusting the child's appetite. ${ }^{15,16}$ The corollary, nonresponsive feeding, is characterized by excess maternal control that overrides these cues through pressure, restriction or reward, and/or emotional feeding (use of food to distract, calm, or comfort), which teaches the child to eat for reasons unrelated to appetite. ${ }^{5,15,17,18}$ Healthy food preferences are developed by exposing infants to a wide variety of textures and healthy foods while also limiting exposure to sweet, salty, and fatty foods. ${ }^{19-22}$ These protective maternal feeding practices are potentially modifiable targets for early obesity prevention interventions. We report on the long-term outcomes (at ages 3.5 and 5 years) of 1 of few randomized controlled trials (RCTs) to have evaluated obesity prevention interventions targeting complementary feeding practices. ${ }^{23-25}$

The NOURISH RCT evaluated anticipatory guidance on protective early feeding practices to first-time mothers of healthy term infants. ${ }^{26}$ We have reported promising short-term, cross-sectional intervention effects on maternal feeding practices and child eating behaviors, food preferences, and BMI Z-scores assessed at 14 months and 2 years of age..$^{27-29}$ Longer-term follow-up is required to determine whether these effects are sustained into the preschool years as children become more autonomous in their food choices and encounter a widening range of food and eating environments. Our aim is to provide longitudinal analysis of intervention effects on maternal feeding practices and child anthropometric indicators of obesity risk across 4 outcome assessment points (14 months and 2, 3.5, and 5 years of age). We predicted that compared with participants allocated to the control group, mothers in the intervention group would demonstrate more protective feeding practices and their infants would have lower BMI Z-scores.

\section{METHODS}

Recruitment occurred in 2008-2009.26,30 A consecutive sample of first-time mothers (aged $\geq 18$ years) with healthy term infants ( $>35$ weeks' gestation, $\geq 2500 \mathrm{~g}$ birth weight) and who could read and speak English was approached on the postnatal wards at 7 maternity hospitals in 2 Australian cities, Brisbane and Adelaide. Mothers who consented to later contact provided demographic data. They were recontacted when their infant was on average 4 months old, at which time those consenting to full enrollment completed baseline assessment and were subsequently independently randomized to intervention or control conditions. At this time, the Kessler Psychological Distress Scale, ${ }^{31}$ a 10 -item self-assessment widely used in population surveys in Australia to screen for risk of psychiatric morbidity, was administered. Mothers in the clinical range were deemed ineligible and referred to their general practitioner. These exclusion criteria aimed to identify "at-risk" mothers for whom a universal group program focused on feeding was potentially inappropriate and might contribute further to maternal stress. The trial was approved by Human Research Ethics Committees $(N=11)$ covering Queensland University of Technology, Flinders University, and all the recruitment hospitals.

\section{Intervention}

The intervention ${ }^{28,29}$ comprised 2 modules commencing when the children were aged 4 to 7 and 13 to 16 months. Each module involved 6 group sessions (40 groups across both modules and sites) of 1- to 2hour duration, conducted over 12 weeks. Sessions were delivered at child health clinics by a dietitian ( $n=$ $13)$ and a psychologist $(n=13)$ who had received standardized training and used comprehensive standardized facilitator materials.

Content focused on healthy eating patterns and growth, rather than obesity prevention. Three aspects of feeding previously associated with healthy child eating behavior and weight status were targeted:

(1) increased exposure to healthy foods and decreased exposure to unhealthy foods to promote the development of healthy food preferences, ${ }^{19-22,32}$ (2) responsive feeding that recognizes and responds appropriately to infant cues of hunger and satiety to promote self-regulation of intake, ${ }^{15,16,18}$ and (3) positive parenting (warmth, encouragement of autonomy, and selfefficacy). ${ }^{33-35}$ We used an anticipatory guidance framework to provide parents with information 
TABLE 1 Baseline Characteristics of 698 Mother-Infant Dyads Allocated to the Control or Intervention Condition of the NOURISH RCT

\begin{tabular}{|c|c|c|c|}
\hline \multirow[t]{2}{*}{ Variable } & Control $(n=346)$ & Intervention $(n=352)$ & Total \\
\hline & \multicolumn{3}{|c|}{$\%$ (count) or M (SD) } \\
\hline \multicolumn{4}{|l|}{ Mother } \\
\hline Education (university degree) & 58 (199) & $59(207)$ & $58(406)$ \\
\hline Smoked during pregnancy (yes) & $11(40)$ & $13(45)$ & $12(85)$ \\
\hline Born in Australia (yes) & $79(270)$ & $78(272)$ & $78(542)$ \\
\hline Married/de facto (yes) & $95(327)$ & $95(332)$ & 95 (659) \\
\hline $\begin{array}{l}\text { SEIFA Index of Relative Advantage } \\
\text { and Disadvantage (relative } \\
\text { disadvantage } \leq 7 \text { th decile) }\end{array}$ & $34(117)$ & $32(113)$ & $33(230)$ \\
\hline Age at delivery (y) & $29.9(5.3)$ & $30.2(5.3)$ & $30.1(5.3)$ \\
\hline BMI & $26.2(5.5)$ & $25.8(5.1)$ & $26.0(5.3)$ \\
\hline \multicolumn{4}{|l|}{ Infant } \\
\hline Gender (female) & $50(173)$ & $51(181)$ & $51(354)$ \\
\hline Birth wt (kg) & $3.5(0.4)$ & $3.5(0.4)$ & $3.5(0.4)$ \\
\hline Birth wt Z-score ${ }^{a}$ & $0.38(0.87)$ & $0.39(0.88)$ & $0.38(0.87)$ \\
\hline Age (mo) & $4.3(1.0)$ & $4.3(1.0)$ & $4.3(1.0)$ \\
\hline$W A Z^{a}$ & $-0.03(0.91)$ & $-0.04(0.93)$ & $-0.04(0.92)$ \\
\hline$H A Z^{a}$ & $0.27(0.95)$ & $0.39(0.98)$ & $0.33(0.97)$ \\
\hline $\mathrm{BMIZ}^{\mathrm{a}}$ & $-0.26(0.98)$ & $-0.36(0.98)$ & $-0.31(0.98)$ \\
\hline \multicolumn{4}{|l|}{ Feeding mode } \\
\hline Fully/exclusively breastfed & $55(170)$ & $60(191)$ & $57(361)$ \\
\hline Formula only & $27(83)$ & $26(84)$ & $27(167)$ \\
\hline Combination (formula and breastfed) & $19(59)$ & $14(44)$ & $16(103)$ \\
\hline Ever breast fed & $96(266)$ & $98(250)$ & $97(516)$ \\
\hline Ever given solids & $34(114)$ & $34(115)$ & 34 (229) \\
\hline Age solids introduced $(w k)^{b}$ & $22.7(4.9)$ & $22.8(4.4)$ & $22.8(4.7)$ \\
\hline
\end{tabular}

about behaviors to expect and constructive ways to manage these, rather than parents seeking advice on established problems. ${ }^{36}$ The control group had self-directed access to universal community child health services, potentially child weighing, and information via the Internet or telephone help line. No data were collected on the frequency with which mothers accessed standard care.

\section{Outcome Measures}

Outcomes were assessed at 5 points (see Fig 1): Time 1 (T1), baseline child age 4 months; Time 2 (T2), child age 14 months and 6 months after completion of Module 1; Time 3 (T3), child age 2 years and 6 months after completion of Module 2; Time 4 (T4), child age 3.5 years; Time 5 (T5), child age 5 years. Times 4 and 5 represent follow-up 2 and 3.5 years, respectively, after intervention completion.

\section{Anthropometry}

Trained research staff, independent of intervention delivery and blinded to participant group, recorded anthropometric measures using standard equipment and protocols. Measurements at T1 through T3 were primarily conducted at child health clinics, whereas most T4 and T5 measurements were undertaken in the participants' homes. At T4 and T5 participants were provided with an AUD25 retail voucher at completion of the anthropometric measurements.

Child weight was measured naked (T1-T3) or in light undergarments (T4-T5). Duplicate child recumbent length (T1-T2) or standing height (T3-T5) and waist circumference weight (T1-T5) were taken.

Standardized (Z-scores) weight-for-age (WAZ), length/height for age (HAZ), and BMI-for-age (BMIZ) were calculated by using the World Health (T3-T5) and single maternal height and
Organization Anthro version 3.0.1 and macros program. As recommended, $0.7 \mathrm{~cm}$ was added to the T3 standing height of children $<2$ years to correct for use of recumbent length in the reference sample. ${ }^{37}$ For children $>5$ years at T5 the World Health Organization AnthroPlus version 1.0.4 was used to calculate Z-scores. Waist circumference Z-score (T5 only) was calculated by using LMSgrowth Microsoft Excel add-in ${ }^{38}$ using British 1990 growth reference data. ${ }^{39}$

Classification as overweight (including obese) at T5 used International Obesity Task Force gender-specific 5-year-old BMI $\left(\mathrm{kg} / \mathrm{m}^{2}\right)$ cutoffs. ${ }^{40}$

\section{Feeding Practices}

At T3-T5 maternal feeding practices were assessed by using 9 scales from self-report measures validated for mothers of children aged $\geq 2$ years. Five scales from the Child Feeding Questionnaire $^{41}$ were administered: perceived responsibility; concern about child weight; restriction; pressure to eat; and monitoring. Four scales from the Parental Feeding Style Questionnaire (PFSQ) ${ }^{42}$ were used: instrumental feeding; encouragement; emotional feeding; and control over eating. Items were scored 1 through 5 , with higher means scores indicating a higher frequency of the feeding practice. All scales showed good internal consistency across T3 through T5 (Cronbach's $\alpha>$.70). At T5, mothers also responded to 12 single items derived from the clinical experience of the investigators. They were used in the observational needs assessment study that informed the intervention design and assessed the use of practical feeding strategies targeted in the intervention. ${ }^{17,27,28}$ These assessed how mothers responded to child refusal of familiar foods (6 nonresponsive; 2 responsive strategies) or unfamiliar foods (4 nonresponsive strategies).

\section{Covariates}

Covariate data were collected by using self-completed questionnaires 


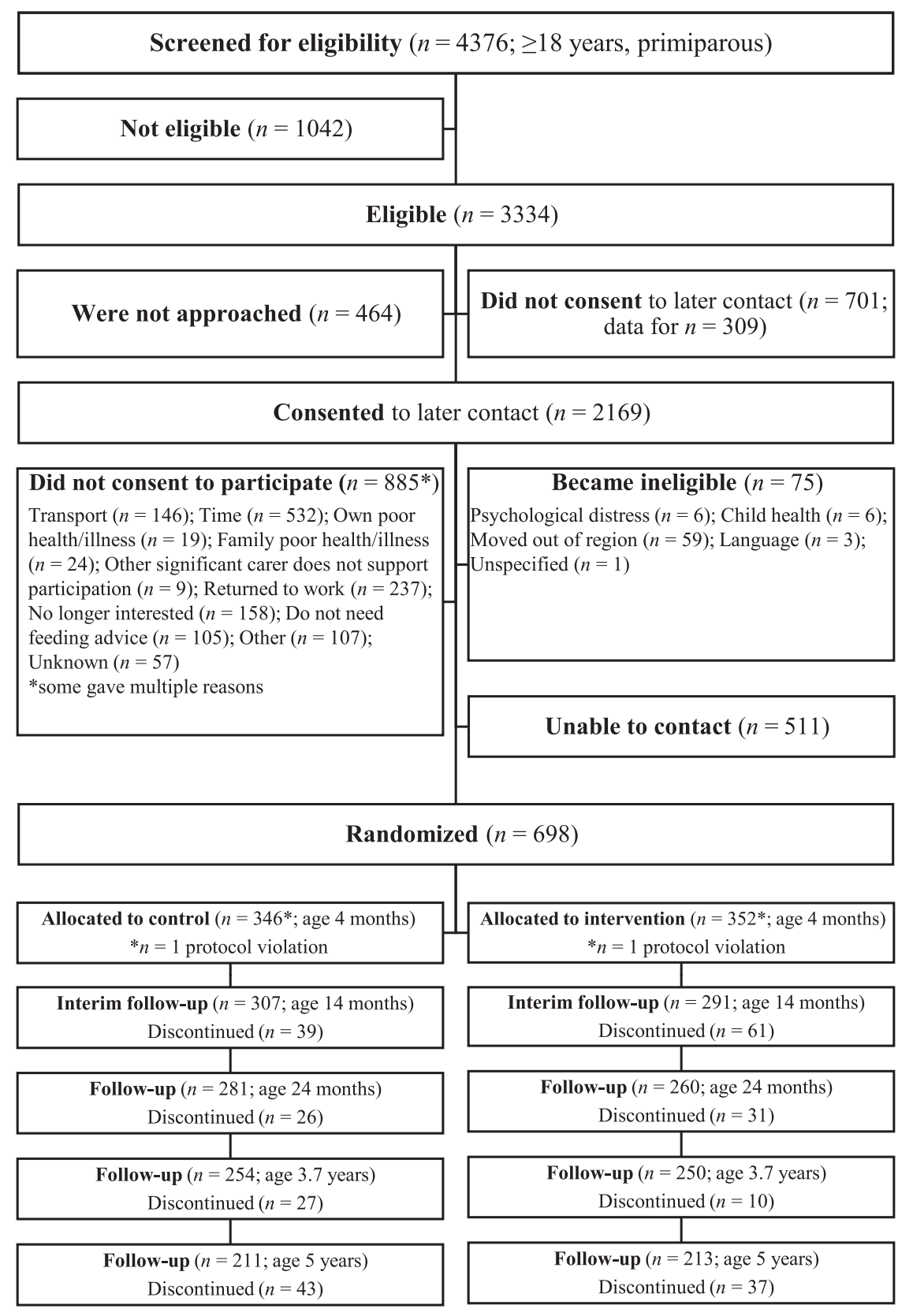

FIGURE 1

CONSORT diagram showing flow of participants. CONSORT, Consolidated Standards of Reporting Trials.

and, for birth weight, hospital records. Socioeconomic status was determined by using Socio-Economic Indexes for Areas (SEIFA) score for the Index of Relative Advantage and Disadvantage. Scores at or below the seventh decile indicated relative disadvantage. ${ }^{43}$

\section{Statistical Analysis}

Sample size and retention at each follow-up are provided in Fig 1. An intention-to-treat approach was used as far as missing data permitted. No imputations for missing data were made. Analysis of longitudinal data using linear mixed models does not require complete data but rather uses all available data irrespective of missing values across time points. There was no evidence of differences by group (intervention vs control) at baseline (Table 1). To assess retention bias at $\mathrm{T} 5$, baseline characteristics between mothers retained/not retained were compared by using likelihood ratio $\chi^{2}$ tests and independent samples $t$ tests for dichotomous and continuous variables, respectively.

Linear mixed models using first-order autoregressive structure with Group, Time (as repeated factor), and their interaction were used to analyze anthropometric data (BMIZ, WAZ, and HAZ T2-T5, adjusting for T1 [baseline] value) and the 9 feeding practices scales (T3-T5). Likelihood ratio $\chi^{2}$ tests were used to assess proportion of children overweight at T5 and mothers' use of the 12 singleitem feeding strategies reported at T5. Longitudinal waist circumference Z-score data were not available, and an independent samples $t$ test was used to compare groups at T5.

Because there was no evidence of group differences (intervention vs control) at baseline, adjustment for covariates (excluding anthropometrics) was not undertaken. Statistical tests were computed by using SPSS Version 21. A $P$ value of .05 (2-tailed) was the criterion for statistical significance.

\section{RESULTS}

\section{Participant Characteristics}

Flow of participants through the trial is shown in Fig 1. Characteristics of 698 mothers and children by group allocation are shown in Table 1 . Mothers who declined participation at second contact were younger $(\mathrm{M}=$ 28.0, $\mathrm{SD}=5.5$ vs $\mathrm{M}=30.1, \mathrm{SD}=5.3$ years), less likely to have a university degree (36\% vs 58\%), less likely to live in a relationship (married/de facto, $90 \%$ vs $95 \%$ ), and more likely to smoke during pregnancy (21\% vs $12 \%$ ). No baseline differences according to group allocation were observed. Mean (SD) child age at follow-up assessments was as follows: (T2) 13.7 (1.3), range 11 to 17 months (51\% female); (T3) 24.1 (0.7), range 21 to 27 months (51\% 
female); (T4) 44.5 (3.1), range 40 to 50 months (52\% female), and (T5) $60.0(0.5)$, range 58 to 65 months (52\% female). Attendance at $\geq 2$ sessions for module 1 was $n=229$ (65\%) and module 2 was $n=130$ (45\% of those retained at module commencement).

Retention (mothers providing any data) at T5 was 61\% (control: $n=211$, intervention: $n=213$ ). Compared with mothers not retained at T5, those retained were slightly older $(\mathrm{M}=30.8, \mathrm{SD}=5.2$ vs $\mathrm{M}=29.0$, $\mathrm{SD}=5.3, P<.001)$, and a greater proportion were in a relationship (married/defacto, 97\% vs 92\%, $P=.01)$, held a university education (68\% vs $42 \%, P<.001$ ), scored $\geq 7$ on the SEIFA index (higher scores indicating relative advantage) (70\% vs $62 \%, P=.03$ ) and reported that they did not smoke during pregnancy ( $90 \%$ vs $84 \%, P=.02$ ). There were no differences between those retained or not retained at T5 for group allocation, country of birth, or maternal BMI, Ps > .05.

\section{Anthropometry}

As shown in Table 2 there was no statistically significant effect of group from T2 to T5 (adjusting for T1 value) on BMIZ (see also Fig 2), WAZ, HAZ, $P s>$.05. Time was significant in each model $(P s<.001)$, but there were no significant Time $\times$ Group interactions
$(P s>.30)$. To assess the potential influence of missing data, BMIZ at T1 was compared for those providing or not providing data at T5 with no differences observed $(P=.54)$. Using gender-specific international BMI cutoffs, ${ }^{40} 11.4 \%$ ( $n=24$ of 211 ) of intervention versus $13.3 \%(n=28$ / 211) of control children were classified as overweight at T5, $P=.66$. Waist circumference Z-score at T5 (control: $\mathrm{M}=0.72, \mathrm{SD}=1.01$ vs $\mathrm{M}=0.67, \mathrm{SD}=0.67$ ) did not differ between groups $(P=.62)$.

\section{Feeding Practices}

Feeding practices scores from T3 to T5 are shown in Tables 3 and 4 . Significant group effects $(P<.05)$ were seen for 6 of 9 scales, with intervention mothers reporting less nonresponsive feeding. Use of specified feeding strategies at T5 are shown in Table 5. Significant group effects $(P<.05)$ were seen for 7 of 12 strategies. In response to children's refusal of food they normally eat, mothers in the intervention group used fewer nonresponsive strategies ( 3 of 6 items) and more responsive strategies (2 of 2 items). In response to child refusal of unfamiliar foods (neophobia), mothers in the intervention group were less likely to disguise the food and more likely to continue to reoffer new foods ( 2 of 4 items).

\section{DISCUSSION}

This is the first report of a long-term follow-up of an RCT evaluating an obesity prevention intervention that targeted feeding practices and started in the first year of life. Mothers allocated to the intervention consistently reported using more protective feeding practices than those receiving usual care. Despite the relative improvements in feeding practices, there were no overall statistically significant intervention (group) effects on anthropometric indicators of obesity risk. However, at all follow-up assessments (T3-T5) the BMI Z-scores of intervention children were $16 \%$ to $17 \%$ lower than control children, with the overall group effect approaching significance $(P=.060)$. The prevalence of overweight/obesity was also not significantly different between groups (control 13.3\% vs intervention $11.4 \%, P=.66$ ). However, this difference translated to a population level would represent a meaningful public health effect.

Nonresponsive feeding practices override the child's hunger and satiety cues and undermine their intrinsic capacity to self-regulate. In healthy children, satiety is typically signaled by refusal of familiar foods. ${ }^{15,17}$ Nonresponsive feeding practices include excess overt control

TABLE 2 Longitudinal Analysis of Child Anthropometric Outcomes From the NOURISH RCT at Child Ages 14 mo and 2, 3.7 , and 5 y

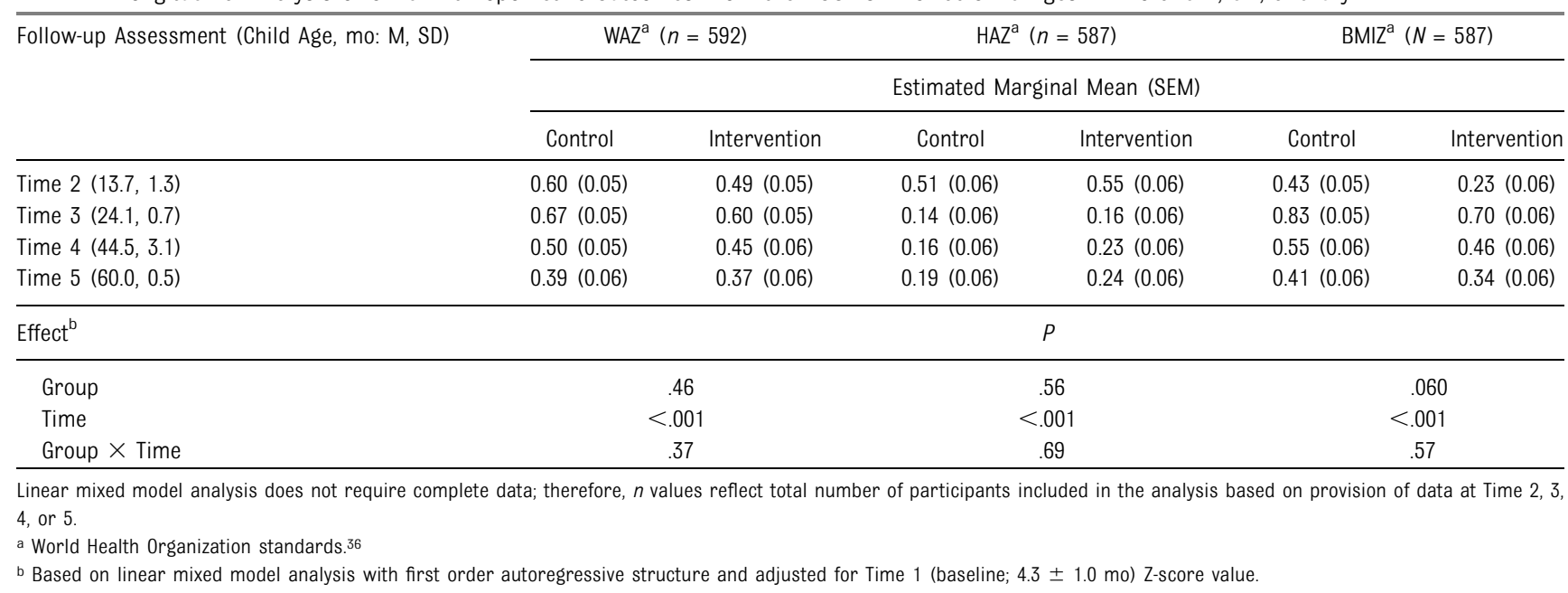




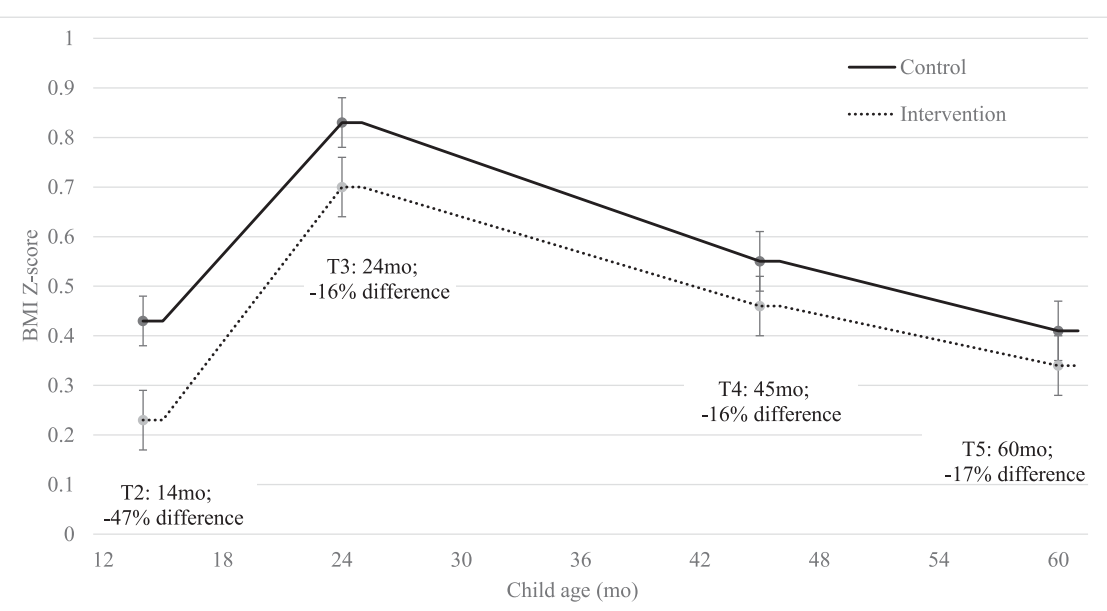

FIGURE 2

Longitudinal analysis of child BMI Z-score ages 14 months and 2, 3.7, and 5 years. Linear mixed model $(n=587)$ using autoregressive structure includes data collected at Time 2 through 5 and adjusts for child BMI $Z$ at baseline (Time 1: 4 months): Group effect $P=.060$; Time $P<.001$; Group $X$ Time $P=.57$. Figure shows estimated marginal means with SE bars.

in feeding (eg, restriction and pressure to eat), explicit encouragement, praise, coercion, coaxing, and the use of rewards for eating. ${ }^{15,16,18}$ In addition, emotional feeding (using food to comfort, calm, or distract) and use of food rewards to shape behavior teach the child to eat for reasons unrelated to appetite. 5,14,15,17 The intervention mothers reported less frequent use of nonresponsive feeding practices on 6 of 9 scales compared with controls. Furthermore, at T5, the proportion of control mothers using inappropriate responses to food refusal was 1.2 to 1.8 times higher for 7 of 12 specified strategies than intervention mothers. Consistent with our previous findings, ${ }^{27,28}$ intervention mothers remained more likely up to 3.5 years after completion of the intervention (child age 5 years) to be using protective feeding practices that have been positively associated with better dietary quality and healthy child eating behaviors and weight status. ${ }^{13,14,44}$
It is important to note that, notwithstanding these strong and consistent intervention effects, half to two-thirds of mothers in both groups reported using counterproductive feeding strategies. Furthermore, the use of coercive strategies in response to general food refusal between $\mathrm{T}^{28}$ and $\mathrm{T} 5$ had roughly almost doubled. These data suggest that mothers need additional age-appropriate support to promote use of protective feeding practices across the preschool years.

Despite a consistent and sustained intervention effect on feeding practices, there was no statistically significant effect on BMIZ. However, group differences were in the expected direction at each point $(P=.06)$, and there is potential for type II error. A 2010 systematic review $^{24}$ of interventions aimed at preventing overweight in children $<2$ years identified 10 studies (3 RCTs). Only 2 of the RCTs (both rated fair quality) ${ }^{45,46}$ evaluated impact of an intervention commencing at $<9$ months of age on weight status and neither showed any significant intervention effects. One study of 101 exclusively formula-fed infants reported no effect of a single education session (child aged 3-10 weeks) on weight gain (grams per week) from 0 to 4 months. ${ }^{45}$ The

TABLE 3 Longitudinal Analysis of Maternal Feeding Practices Assessed With the Child Feeding Questionnaire ${ }^{40}$ at Child Ages 2, 3.7 , and 5 y

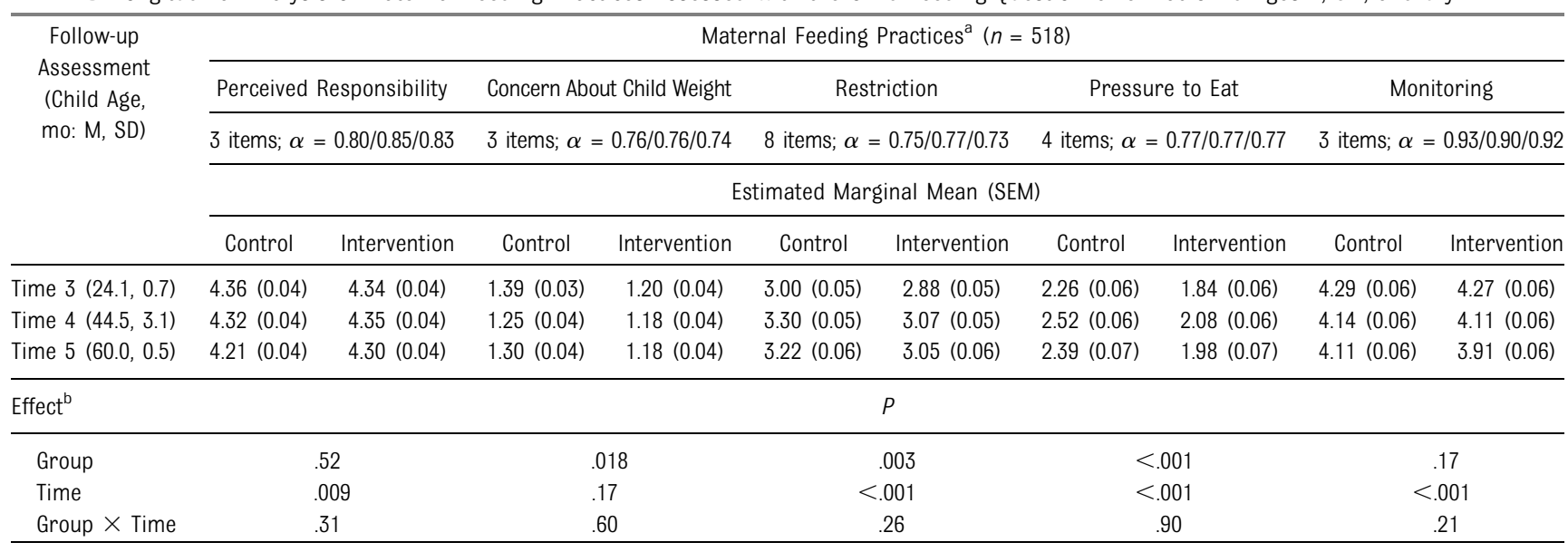

Data are not available before Time 3 because tool was not valid in children aged $<2$ y. Linear mixed model analysis does not require complete data; therefore, $n$ values reflect total number of participants included in the analysis based on provision of data at Time 3, 4, or 5. $\alpha=$ Cronbach $\alpha$ at Time 3/Time 4/Time 5 .

a Measured on a Likert-style scale (1-5) with higher scores indicating greater use of the feeding practice.

b Based on linear mixed model analysis with first order autoregressive structure. 
TABLE 4 Longitudinal Analysis of Maternal Feeding Practices Assessed With the Parental Feeding Style Questionnaire ${ }^{41}$ at Child Ages 2, 3.7 , and 5 y

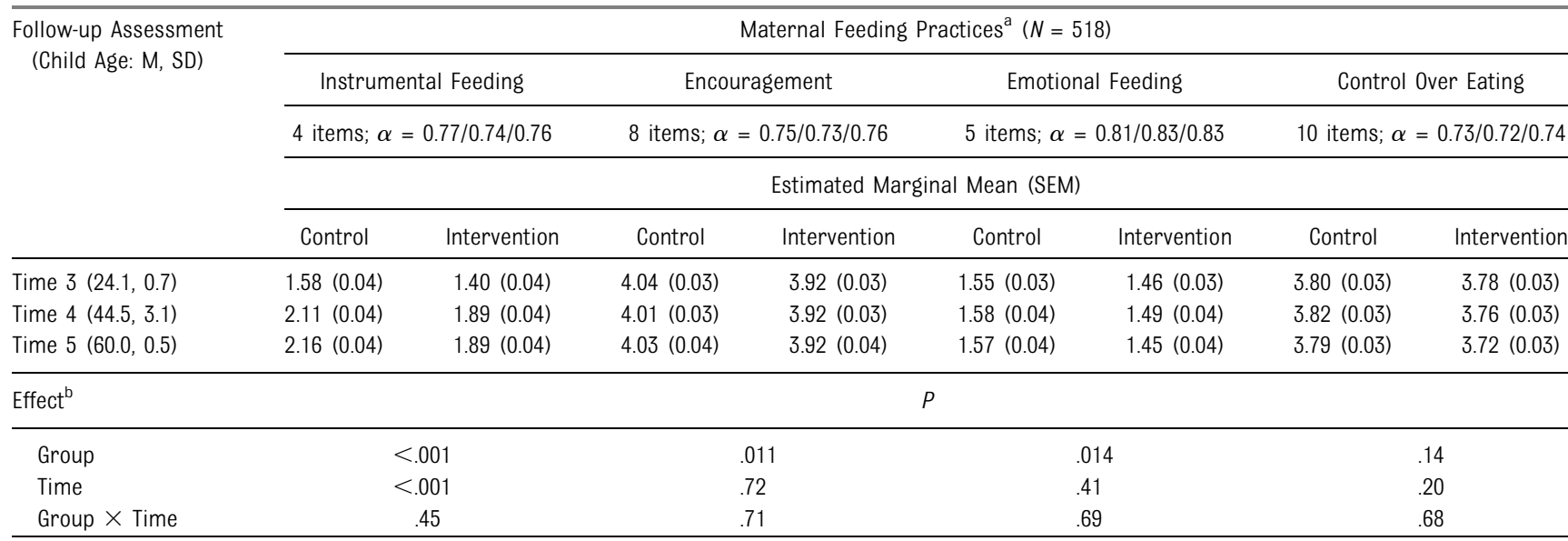

Data are not available before Time 3 because tool is not valid in children aged $<2$ y. Linear mixed model analysis does not require complete data; therefore, $N$ value reflects total number of participants included in the analysis based on provision of data at Time 3, 4, or 5. $\alpha=$ Cronbach $\alpha$ Time 3/Time 4/Time 5 .

a Measured on a Likert-style scale (1-5) with higher scores indicating greater use of the feeding practice.

${ }^{b}$ Based on linear mixed model analysis with first order autoregressive structure.

other study, 46 although large

$(n=1062)$, targeted dietary fat and

cholesterol intake and atherosclerosis

risk factor outcomes, rather than

obesity prevention.

Since the Ciampa review, ${ }^{24}$ only $3^{47-49}$ RCTs have reported weight status after an obesity prevention intervention commencing in infancy. All targeted first-time mothers. Paul et $\mathrm{al}^{49}$ reported a significant effect on weight-for-length percentiles at 12 months of age (33rd vs 50 th, retention $69 \% ; n=22$ vs 30 ) of an intervention comprising 3 nurse home visits targeting soothing strategies and process of solid introduction. Two other large Australian trials ${ }^{47,48}$ have reported outcomes at $\sim 2$ years of age. The Healthy Beginnings Trial ${ }^{48}$ evaluated 6 nurse home visits during the first 2 years of life. They reported a small but statistically significant difference in BMI (2.3\%; retention 75\%; $n=497)$ but did not report or control for birth weight or baseline BMI. In contrast, the
Infant Feeding Activity and Nutrition Trial (INFANT) cluster RCT ${ }^{47}$ evaluated an intervention delivered by researchers to preexisting mothers' groups and reported no effect on BMIZ after adjusting for baseline values (mean difference 0.02 BMIZ units; retention $86 \%$; $n=542$ ). None of these trials have reported comparable feeding practices data, and to date, none have reported outcomes beyond 2 years of age.

TABLE 5 Feeding Strategies Used By Mothers in Response to Food Refusal at Child Age 5 y (Time 5, $n=392$ )

\begin{tabular}{|c|c|c|c|}
\hline \multirow[t]{2}{*}{ Feeding Strategies } & Control $(n=194)$ & Intervention $(n=198)$ & $P$ \\
\hline & \multicolumn{3}{|c|}{$\%(n)$} \\
\hline \multicolumn{4}{|l|}{ Response to refusal of familiar foods ${ }^{a}$} \\
\hline \multicolumn{4}{|l|}{ Nonresponsive feeding strategies—override satiety cues } \\
\hline Insist child eats it $(n=390)$ & $65(126)$ & $48(94)$ & .001 \\
\hline Offer milk drink instead $(n=391)$ & $6(11)$ & $3(6)$ & .22 \\
\hline Offer liked food instead $(n=389)$ & $41(78)$ & $37(72)$ & .47 \\
\hline \multicolumn{4}{|l|}{ Encourage to eat } \\
\hline Feed child with spoon/fork $(n=391)$ & $53(103)$ & $42(84)$ & .034 \\
\hline Offer food reward $(n=390)$ & $63(120)$ & $42(83)$ & $<.001$ \\
\hline Offer nonfood reward $(n=390)$ & $39(74)$ & $29(58)$ & .055 \\
\hline \multicolumn{4}{|l|}{ Responsive feeding strategies-respond appropriately to satiety cues } \\
\hline Offer no food until next usual meal/snack time $(n=391)$ & $64(123)$ & $77(152)$ & .006 \\
\hline Accept that child may not be hungry; take food away $(n=389)$ & $79(152)$ & $88(173)$ & .014 \\
\hline \multicolumn{4}{|l|}{ Response to refusal of unfamiliar foods (neophobia) ${ }^{\mathrm{b}}$} \\
\hline Assume child dislikes; do not offer again $(n=382)$ & $14(27)$ & $13(25)$ & .88 \\
\hline Disguise food $(n=382)$ & $53(102)$ & $41(78)$ & .018 \\
\hline Offer with liked food $(n=391)$ & $92(178)$ & $93(184)$ & .85 \\
\hline Times offered a food before deciding whether liked ( $\leq 6$ times) & $55(107)$ & $39(77)$ & .002 \\
\hline
\end{tabular}

$n$ values given where $n<392$ due to missing data. Dichotomous variables based on likelihood ratio $\chi^{2}$ test; \% within group ( $n$ ) reported.

a Response options: $1=$ never to $5=$ most of the time, dichotomized to (1,2 vs) $3,4,5$ and \% reported.

b Response options: $1=$ never to $4=$ often, dichotomized to $(1,2$ vs. $) 3,4$ and $\%$ reported. 
NOURISH, like the 2 other Australian trials, ${ }^{47,48}$ was a universal intervention offered to first-time mothers, irrespective of maternal or child obesity status/risk. However, infants exposed to the established prenatal and postnatal obesity risk factors may be particularly vulnerable to the obesogenic environment and thus may be more responsive to early prevention interventions. ${ }^{50}$ Established risk factors such as parent weight status, maternal nutrition, excess gestational weight gain, formula feeding, and rapid early weight gain may induce epigenetic processes that in turn increase susceptibility to obesity. 1,3,4 Emerging evidences suggest other heritable infant factors may also confer increased obesity risk. A recent twin study ${ }^{51}$ has shown that exclusively breastfed infants at 3 months of age, identified by their mothers as having a big appetite (higher food responsiveness and lower satiety responsiveness), gained more weight from 0 to 15 months, with weight trajectory differences apparent as early as 3 months. Temperament phenotypes may also influence feeding practices, eating behavior, and weight status. ${ }^{52-54}$ The complex genetic, biological, and behavioral interactions between these maternal and child risk factors may be further moderated by other exposures such as age of complementary feeding, early food exposure, and responsive feeding practices. ${ }^{1,4}$ In the context of this emerging evidence, it is possible that the protective feeding practices used more often by our intervention mothers only translate to measurable outcomes in child weight status when variability in genetic or phenotypic vulnerability is considered.

Interventions to modify early feeding environments may show greatest effect if targeted to families presenting with existing obesity risk factors. ${ }^{50}$

The strengths and limitations of the NOURISH RCT have been discussed elsewhere. ${ }^{27-29}$ Strengths include a Consolidated Standards of Reporting Trials-standard RCT, a large sample size, and single-blind independent assessors. Limitations include self-report feeding practices data and lack of a true attention control, whereby both the groups had matched exposure to both a peer group and health professional. The NOURISH RCT, in common with most trials, shows evidence of selection and retention biases. These do not affect internal validity but potentially limit generalizability. The bias toward older, more educated mothers and hence families with lower obesity risk, may have attenuated intervention response. The prevalence of overweight in the control children at 5 years of age was well below population prevalence ( $13 \%$ vs $24 \%$ ), 55 confirming that overall, the level of obesity risk was comparatively lower in the study sample.

There was also a disappointing level of attendance at Module 2 (only $45 \%$ of those retained at Time 2 attended $\geq 2$ sessions). This may have further tempered intervention response and suggests the need to reconsider how to optimally deliver anticipatory guidance to mothers of toddlers, many of whom have returned to paid employment.

\section{CONCLUSIONS}

Our findings indicate that anticipatory guidance was effective in promoting protective maternal feeding practices with intervention effects maintained $>3$ years after intervention completion. These sustained effects translated into commensurate trends in obesity risk but not statistically significant differences. NOURISH was a universal intervention, and it may be that interventions targeted to infants with greater susceptibility to epigenetic effects and subsequent obesity may be more effective. The increasing prevalence of nonresponsive feeding strategies with age in both groups suggests that additional guidance regarding protective feeding practices is required beyond toddlerhood. Overall, the results suggest that investing in early advice on the "how" of responsive complementary feeding can improve maternal feeding practices and may have positive effects on obesity risk up to 5 years of age.

\section{ACKNOWLEDGMENTS}

We acknowledge the NOURISH investigators, study staff and participants.

ABBREVIATIONS
BMIZ: BMI-for-age Z-score
HAZ: length/height-for-age Z-score
RCT: randomized controlled trial
SEIFA: Socio-Economic Indexes for
$\quad$ Areas
WAZ: weight-for-age Z-score

Address correspondence to Lynne Daniels, PhD, School of Exercise and Nutrition Sciences, Queensland University of Technology, Victoria Park Road, Kelvin Grove, Queensland, Australia, 4059. E-mail: I2.daniels@qut.edu.au

PEDIATRICS (ISSN Numbers: Print, 0031-4005; Online, 1098-4275)

Copyright (C) 2015 by the American Academy of Pediatrics

FINANCIAL DISCLOSURE: The authors have indicated they have no financial relationships relevant to this article to disclose.

FUNDING: NOURISH was funded from 2008 through 2014 by 2 consecutive grants from the Australian National Health and Medical Research Council (426704, APP1021065). Additional funding was provided by HJ Heinz (postdoctoral fellowship to KM), Meat \& Livestock Australia, Department of Health South 
Australia, Food Standards Australia New Zealand, Queensland University of Technology, and the Roberta Holmes Transition to Contemporary Parenthood Program (to JN).

POTENTIAL CONFLICT OF INTEREST: The authors have indicated they have no potential conflicts of interest to disclose.

\section{REFERENCES}

1. World Health Organization. Report of the First Meeting of the Ad hoc Working Group on Science and Evidence for Ending Childhood Obesity. Geneva, Switzerland: World Health Organization; 2014. Available at: http://www.who.int/ end-childhood-obesity/commissioners/ first-meeting-report/en. Accessed April 9, 2015

2. Garner AS, Shonkoff JP; Committee on Psychosocial Aspects of Child and Family Health; Committee on Early Childhood, Adoption, and Dependent Care; Section on Developmental and Behavioral Pediatrics. Early childhood adversity, toxic stress, and the role of the pediatrician: translating developmental science into lifelong health. Pediatrics. 2012;129(1). Available at: www.pediatrics. org/cgi/content/full/129/1/e224

3. Lillycrop KA, Burdge GC. Epigenetic changes in early life and future risk of obesity. Int J Obes (Lond). 2011;35(1): 72-83

4. Pérez-Escamilla R, Kac G. Childhood obesity prevention: a life-course framework. Int J Obes Suppl. 2013;3 (suppl 1):S3-S5

5. Birch LL. Child feeding practices and the etiology of obesity. Obesity (Silver Spring). 2006;14(3):343-344

6. Wardle J, Carnell S, Haworth CM, Plomin R. Evidence for a strong genetic influence on childhood adiposity despite the force of the obesogenic environment. Am J Clin Nutr. 2008;87(2): 398-404

7. Nicklaus S, Remy E. Early origins of overeating: tracking between early food habits and later eating patterns. Curr Obesity Rep. 2013;2(2):179-184

8. Kramer MS. Breastfeeding, complementary (solid) foods, and longterm risk of obesity. Am J Clin Nutr. 2010; 91(3):500-501

9. Horta BL, Bahl R, Martines JC, et al. Evidence on the Long-Term Effects of Breastfeeding: Systematic Reviews and Meta-Analyses. Geneva, Switzerland: World Health Organization; 2007
10. Kramer M, Kakuma R. Optimal duration of exclusive breastfeeding. Cochrane Database Syst Rev. 2002;(8):CD003517

11. Skinner JD, Carruth BR, Bounds W, Ziegler P, Reidy K. Do food-related experiences in the first 2 years of life predict dietary variety in school-aged children? J Nutr Educ Behav. 2002;34(6): 310-315

12. Skinner JD, Carruth BR, Wendy B, Ziegler PJ. Children's food preferences: a longitudinal analysis. J Am Diet Assoc. 2002;102(11):1638-1647

13. Vereecken C, Rovner A, Maes L. Associations of parenting styles, parental feeding practices and child characteristics with young children's fruit and vegetable consumption. Appetite. 2010;55(3):589-596

14. Anzman SL, Birch LL. Low inhibitory control and restrictive feeding practices predict weight outcomes. J Pediatr. 2009 155(5):651-656

15. DiSantis KI, Hodges EA, Johnson SL, Fisher J0. The role of responsive feeding in overweight during infancy and toddlerhood: a systematic review. Int J Obes (Lond). 2011;35(4):480-492

16. Eneli IU, Crum PA, Tylka TL. The trust model: a different feeding paradigm for managing childhood obesity. Obesity (Silver Spring). 2008;16(10): 2197-2204

17. Chan L, Magarey AM, Daniels LA. Maternal feeding practices and feeding behaviors of Australian children aged 12-36 months. Matern Child Health J. 2011;15(8):1363-1371

18. Hurley KM, Cross MB, Hughes S0. A systematic review of responsive feeding and child obesity in high-income countries. J Nutr. 2011;141(3):495-501

19. Benton D. Role of parents in the determination of the food preferences of children and the development of obesity. Int J Obes Relat Metab Disord. 2004; 28(7):858-869

20. Cooke L. The importance of exposure for healthy eating in childhood: a review. J Hum Nutr Diet. 2007;20(4):294-301
21. Dovey TM, Staples PA, Gibson EL, Halford JC. Food neophobia and "picky/fussy" eating in children: a review. Appetite. 2008;50(2-3):181-193

22. Wardle J, Cooke L. Genetic and environmental determinants of children's food preferences. Br J Nutr. 2008;99(suppl 1):S15-S21

23. Askie LM, Baur LA, Campbell K, et al; EPOCH Collaboration Group. The Early Prevention of Obesity in CHildren (EPOCH) Collaboration - an individual patient data prospective meta-analysis. BMC Public Health. 2010;10(1):728

24. Ciampa PJ, Kumar D, Barkin SL, et al. Interventions aimed at decreasing obesity in children younger than 2 years: a systematic review. Arch Pediatr Adolesc Med. 2010;164(12): 1098-1104

25. Yanovski JA. Intervening during infancy to prevent pediatric obesity. Obesity (Silver Spring). 2011;19(7):1321-1322

26. Daniels LA, Magarey A, Battistutta D, et al. The NOURISH randomised control trial: positive feeding practices and food preferences in early childhood a primary prevention program for childhood obesity. BMC Public Health. 2009;9:387

27. Daniels LA, Mallan KM, Battistutta D, Nicholson JM, Perry R, Magarey A. Evaluation of an intervention to promote protective infant feeding practices to prevent childhood obesity: outcomes of the NOURISH RCT at 14 months of age and 6 months post the first of two intervention modules. Int $J$ Obes (Lond). 2012;36(10):1292-1298

28. Daniels LA, Mallan KM, Nicholson JM, Battistutta D, Magarey A. Outcomes of an early feeding practices intervention to prevent childhood obesity. Pediatrics. 2013;132(1). Available at: www.pediatrics. org/cgi/content/full/132/1/e109

29. Daniels LA, Mallan KM, Battistutta D, et al. Child eating behavior outcomes of an early feeding intervention to reduce risk indicators for child obesity: the NOURISH RCT. Obesity (Silver Spring). 2014;22(5):E104-E111 
30. Daniels LA, Wilson JL, Mallan KM, et al. Recruiting and engaging new mothers in nutrition research studies: lessons from the Australian NOURISH randomised controlled trial. Int J Behav Nutr Phys Act. 2012;9(1):129

31. Kessler RC, Andrews G, Colpe LJ, et al. Short screening scales to monitor population prevalences and trends in non-specific psychological distress. Psychol Med. 2002;32(6):959-976

32. Maier A, Chabanet C, Schaal B, et al. Effects of repeated exposure on acceptance of initially disliked vegetables in 7-month old infants. Food Qual Prefer. 2007;18(8):1023-1032

33. Wake M, Nicholson JM, Hardy $P$, et al. Preschooler obesity and parenting styles of mothers and fathers: Australian national population study. Pediatrics. 2007;120(6). Available at: www.pediatrics. org/cgi/content/full/120/6/e1520

34. Jansen E, Daniels L, Nicholson J. The dynamics of parenting and early feeding - constructs and controversies: a viewpoint. Early Child Dev Care. 2012; 182(8):967-981

35. Patrick H, Nicklas TA, Hughes SO, Morales $M$. The benefits of authoritative feeding style: caregiver feeding styles and children's food consumption patterns. Appetite. 2005;44(2):243-249

36. Nelson CS, Wissow LS, Cheng TL. Effectiveness of anticipatory guidance: recent developments. Curr Opin Pediatr. 2003;15(6):630-635

37. WHO Child Growth Standards: Iength/ height-for-age, weight-for-age, weightfor-length, weight-for-height and body mass index-for-age: methods and development. Geneva, Switzerland: World Health Organization; 2006

38. Pan H, Cole TJ. LMSgrowth, a Microsoft Excel add-in to access growth references based on the LMS method. Version 2.77 2012. Available at: www.healthforallchidlren. co.uk. Accessed July 1, 2014
39. McCarthy HD, Jarrett KV, Crawley HF. The development of waist circumference percentiles in British children aged 5.0-16.9 y. Eur J Clin Nutr. 2001;55(10): 902-907

40. Cole TJ, Bellizzi MC, Flegal KM, Dietz WH. Establishing a standard definition for child overweight and obesity worldwide international survey. BMJ. 2000; 320(7244):1240-1243

41. Birch LL, Fisher J0, Grimm-Thomas K, Markey CN, Sawyer R, Johnson SL. Confirmatory factor analysis of the Child Feeding Questionnaire: a measure of parental attitudes, beliefs and practices about child feeding and obesity proneness. Appetite. 2001;36(3): 201-210

42. Wardle J, Sanderson S, Guthrie CA, Rapoport L, Plomin R. Parental feeding style and the inter-generational transmission of obesity risk. Obes Res. 2002;10(6):453-462

43. Trewin D. Socio-Economic Indexes for Areas (SEIFA). Canberra, Australia: Australian Bureau of Statistics; 2001

44. Gubbels JS, Kremers SPJ, Stafleu A, et al Diet-related restrictive parenting practices. Impact on dietary intake of 2year-old children and interactions with child characteristics. Appetite. 2009; 52(2) :423-429

45. Kavanagh KF, Cohen RJ, Heinig MJ, Dewey KG. Educational intervention to modify bottle-feeding behaviors among formulafeeding mothers in the WIC program: impact on infant formula intake and weight gain. J Nutr Educ Behav. 2008; 40(4):244-250

46. Simell 0, Niinikoski H, Rönnemaa $T$, et al. Special Turku Coronary Risk Factor Intervention Project for Babies (STRIP). Am J Clin Nutr. 2000;72(5 Suppl): 1316S-1331S

47. Campbell KJ, Lioret S, McNaughton SA, et al. A parent-focused intervention to reduce infant obesity risk behaviors: a randomized trial. Pediatrics. 2013; 131(4):652-660

48. Wen LM, Baur LA, Simpson JM, Rissel C, Wardle K, Flood VM. Effectiveness of home based early intervention on children's BMl at age 2: randomised controlled trial. BMJ. 2012;344:e3732

49. Paul IM, Savage JS, Anzman SL, et al Preventing obesity during infancy: a pilot study. Obesity (Silver Spring). 2011;19(2): 353-361

50. Belsky DWP. Appetite for prevention: genetics and developmental epidemiology join forces in obesity research. JAMA Pediatr. 2014;168(4): 309-311

51. Llewellyn CHP, Trzaskowski M, van Jaarsveld CHMP, Plomin R, Wardle J. Satiety mechanisms in genetic risk of obesity. JAMA Pediatr. 2014;168(4): 338-344

52. Anzman-Frasca S, Stifter CA, Birch LL. Temperament and childhood obesity risk: a review of the literature. J Dev Behav Pediatr. 2012;33(9): 732-745

53. McMeekin S, Jansen E, Mallan K, Nicholson J, Magarey A, Daniels L. Associations between infant temperament and early feeding practices. A cross-sectional study of Australian mother-infant dyads from the NOURISH randomised controlled trial. Appetite. 2013;60(1):239-245

54. Vollrath ME, Stene-Larsen K, Tonstad S Rothbart MK, Hampson SE. Associations between temperament at age 1.5 years and obesogenic diet at ages 3 and 7 years. J Dev Behav Pediatr. 2012;33(9): 721-727

55. Australian Bureau of Statistics. Australian Health Survey: Updated results 2011-12. Canberra, Australia: 2013. Available at: http://www.abs.gov. au/ausstats/abs@.nsf/Lookup/ 4364.0.55.003main+features12011-2012. Accessed April 9, 2015 
An Early Feeding Practices Intervention for Obesity Prevention

Lynne Allison Daniels, Kimberley Margaret Mallan, Jan Maree Nicholson, Karen

Thorpe, Smita Nambiar, Chelsea Emma Mauch and Anthea Magarey

Pediatrics 2015;136;e40; originally published online June 8, 2015;

DOI: $10.1542 /$ peds. $2014-4108$

\section{Updated Information \&} Services

References

Citations

Subspecialty Collections

Permissions \& Licensing

Reprints including high resolution figures, can be found at: /content/136/1/e40.full.html

This article cites 47 articles, 8 of which can be accessed free at: /content/136/1/e40.full.html\#ref-list-1

This article has been cited by 2 HighWire-hosted articles: /content/136/1/e40.full.html\#related-urls

This article, along with others on similar topics, appears in the following collection(s):

Nutrition

/cgi/collection/nutrition_sub

Obesity

/cgi/collection/obesity_new_sub

Information about reproducing this article in parts (figures, tables) or in its entirety can be found online at:

/site/misc/Permissions.xhtml

Information about ordering reprints can be found online:

/site/misc/reprints.xhtml

PEDIATRICS is the official journal of the American Academy of Pediatrics. A monthly publication, it has been published continuously since 1948. PEDIATRICS is owned, published, and trademarked by the American Academy of Pediatrics, 141 Northwest Point Boulevard, Elk Grove Village, Illinois, 60007. Copyright @ 2015 by the American Academy of Pediatrics. All rights reserved. Print ISSN: 0031-4005. Online ISSN: 1098-4275.

\section{American Academy of Pediatrics}

DEDICATED TO THE HEALTH OF ALL CHILDREN ${ }^{m}$ 


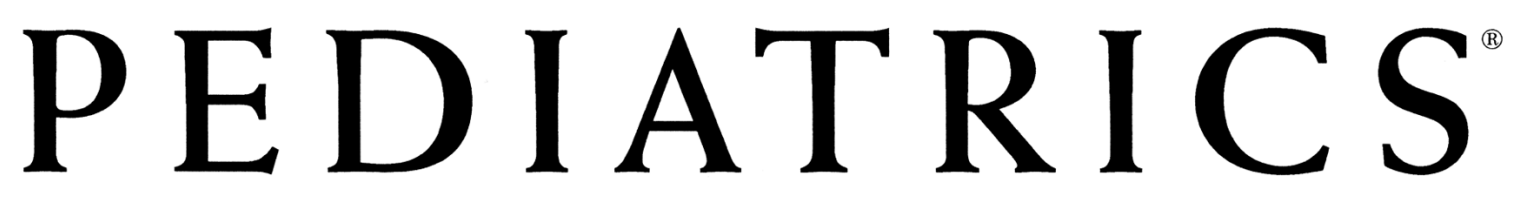

OFFICIAL JOURNAL OF THE AMERICAN ACADEMY OF PEDIATRICS

An Early Feeding Practices Intervention for Obesity Prevention

Lynne Allison Daniels, Kimberley Margaret Mallan, Jan Maree Nicholson, Karen Thorpe, Smita Nambiar, Chelsea Emma Mauch and Anthea Magarey

Pediatrics 2015;136; e40; originally published online June 8, 2015;

DOI: $10.1542 /$ peds.2014-4108

The online version of this article, along with updated information and services, is located on the World Wide Web at: /content/136/1/e40.full.html

PEDIATRICS is the official journal of the American Academy of Pediatrics. A monthly publication, it has been published continuously since 1948. PEDIATRICS is owned, published, and trademarked by the American Academy of Pediatrics, 141 Northwest Point Boulevard, Elk Grove Village, Illinois, 60007. Copyright (@) 2015 by the American Academy of Pediatrics. All rights reserved. Print ISSN: 0031-4005. Online ISSN: 1098-4275.

\section{American Academy of Pediatrics}

DEDICATED TO THE HEALTH OF ALL CHILDREN ${ }^{\mathrm{m}}$ 